Article type: Original Article

\title{
Application of Smart Honeycomb Structures for Automotive Passive Safety
}

\author{
Olga A. Ganilova ${ }^{1}$, Jia J. Low ${ }^{2}$ \\ ${ }^{1}$ Department of Mechanical and Aerospace Engineering, University of Strathclyde, \\ Glasgow, G1 1XJ \\ ${ }^{2}$ Department of Mechanical Engineering, University of Manchester, Manchester, M13 \\ 9PL
}

\section{Corresponding author:}

Olga A. Ganilova, Department of Mechanical and Aerospace Engineering, University of Strathclyde, Glasgow, G1 1XJ, olga.ganilova@strath.ac.uk

\begin{abstract}
Nowadays, most energy absorbing devices used in industry absorb energy through permanent deformation. In some cases, consumers have to repair or even replace energy absorbers even after a mild collision. The work presented in this paper proposes a novel re-usable solution in the form of a hybrid bumper-crush can design where a recoverable structure is integrated into the bumper beam and crush can for a mild collision situation in addition to the traditional energy absorbers recommended for more severe collisions. The main investigation is focused around the performance and optimisation of Negative Stiffness honeycomb, the recoverable structure and honeycomb-filled elements. A comprehensive study was undertaken to investigate numerically the behaviour of these energy absorbing structures under crash conditions, corresponding to real scenarios and simulated using a specially developed finite element model.
\end{abstract}

Key words: Passive safety, Honeycomb, Smart Structures

\section{Introduction}

As modern society is relying heavily on road transport, death and injury due to car crashes has become a major concern to the public. In recent years, continuous effort has been implemented by scientists and engineers to improve general vehicle safety [1].

Crumple zones in vehicles have been introduced with the objective to attenuate the effect of impact on passengers and structures. Increased attention has been given to 
the development of new designs of energy absorbing devices such as crush cans and bumper beams to improve their crashworthiness and energy absorption capability [2-10, 11-13]. There has been a lot of research in the area of smart materials which might begin to find its place in future active applications [14-16]. A crumple zone, on the other hand, is designed to crumple and deform permanently in order to absorb energy when impact occurs. Located at the front, back and sides of a vehicle, it absorbs impact energy before it reaches the safety cell. This significantly reduces the level of impulse force on the safety cage and the passengers by increasing the time of impact. Most crashes involve frontal collisions. This explains the reason that the front crumple zone is often designed to be much larger than the side and rear crumple zones. The energy absorbing ability of the front end is further improved with the application of crush cans. These are designed to deform in an efficient way to absorb large amount of impact energy within a confined space. Most of the time they are found behind the front bumper beam. This ensures that force can be distributed to both crush cans when impact occurs in a multi-directional way.

The variety of research dedicated to energy absorbing elements (EAE) can be classified in dependence on the shape and material of EAEs as well as the presence of filling. Collapsible EAEs of different shapes such as square tubes, circular tubes, struts, honeycombs and sandwich plates [6] are commonly found. The choice of the shape is driven by the manufacturers' criteria for design, the required energy absorbing capability and the cost of the element. Square and circular [17] tubes are widely applied in many transport applications ranging from rail, road and aerospace, due to inexpensive associated manufacturing processes. Nevertheless, studies show that sandwich plates incorporate the highest energy absorption capability as they possess high strength whilst being lightweight [18]. These structures are often tested using various loading methods such as axial impact, lateral indentation, lateral compression, splitting, and inversion. When subjected to axial loading, thin walled EAEs such as honeycombs, and circular and square tubes were found to perform optimally, absorbing marginally more energy than in other loading conditions [18,19,20,17]. Folding and buckling are found to be the most efficient way of deformation and maximum energy absorption [18]. All of the tested structures underwent permanent deformation up to a maximum amount of absorbed energy (to destruction).

Development of modern energy absorbing structures (EAS) has started to be more focused on the ratio of the energy absorbing capability to component weight. Automotive manufacturers such as Ford, have developed a simple, compact diamond square shaped crush can which is lightweight yet strong in its energy absorption capability [7]. The optimised design of this shape allows compression in the most efficient manner under both high and low speed impact conditions [21]. In recent years there have been a number of patents which have been dedicated to the development of innovative energy absorbers. Such research has mainly been concentrated around the modification and optimisation of crush can and bumper beam performance. For example, the General Electric Company invented a bumper beam represented by an injection moulded thermoplastic beam [8]. The bumper beam consisted of a fascia that covered a portion of the beam to spread out the impacting energy to the supporting crush cans. Due to the combination of the crush can and the bumper beam, this design was successful and resulted in an increase of the energy absorbing capability such that the impact force could be spread evenly throughout 
the structure. However, this could potentially lead to high maintenance cost given that the whole structure has to be replaced if either the crush cans or the bumper beam is damaged.

Special attention is paid to the honeycomb since it possesses a higher strength to weight ratio when compared to other designs. It can be present in beams, as a filler in crush cans or even laminated between plates as a sandwich honeycomb. The application of sandwich honeycomb as an energy absorber is a popular approach in modern premium cars due to a very high weight to energy absorption ratio. The sandwich honeycomb, supported by its thin, stiff and strong skin, is proven to be even stronger than a conventional exposed honeycomb [22]. Quite often the strength of the honeycomb core is limited as it has to undergo maximum deformation upon impact loading in order to guarantee optimal energy absorption. Honeycomb cores that are too stiff perform poorly in energy absorbing tests upon low speed collision. This suggests that a simple increase in the strength of the material would not necessarily result in an optimal performance. Thus, material optimisation is crucial, as well as the design of the core itself. However, it should be noted that material optimisation is the most efficient way to improve the energy absorbing properties of the honeycombs without an increment in size or weight.

Extensive investigations into various honeycomb filled structures have been performed over the years [23,10,24,25]. Structures such as hexagonal tubes, circular tubes and bi-hexagonal tubes have been compared. Among the structures studied an optimised honeycomb filled tube [10] has been shown to have the highest energy absorption capability. According to [26] structures absorb significantly more energy when loaded axially. Comparing results from different studies [10,24,25], it is possible to conclude that specific energy absorption (SEA) increases as the density of the cell increases. However, structures with dense honeycomb fillers perform poorly since they are not suitable for different types of impact loading [25]. Optimised versions, where the weight and geometry of the honeycomb filled structures have been optimised for a certain scenario, as discussed in $[9,10]$, show marginally better performance than non-optimised structures [25].

Studies dedicated to material variation [7,10,20,24,25] show that aluminium alloy is the most commonly used material for both main structure and fillers. Study from [27] shows that steel has higher energy absorption per unit weight than aluminium alloy. This can be explained by its significantly higher strength comparing to aluminium alloy. However, aluminium alloy is still widely used as the main structural material for energy absorbers because it is generally much lighter than steel and can provide sufficient energy absorption during collision. Impact cases for composite structures, using materials such as carbon fibre, graphite and Kelvar, are investigated in [28]. Unlike aluminium alloy these composites absorb energy through fracture failure modes, not through buckling. Although energy absorption of composite structures is much higher than for aluminium alloys, their manufacturing and maintenance cost is also significantly higher. Thus, in automotive manufacturing, aluminium alloy is more commonly used than composite materials.

The energy absorbing capability of structures can be further improved by the presence of fillings. Foam and honeycombs are the most commonly found fillers in modern industry $[10,24,25,29,30]$. Without the addition of significant weight to the main structure these fillings are found to provide a significant improvement in energy 
absorption capability [30]. With the application of fillers, the size of an energy absorber can be significantly reduced without sacrificing its energy absorption performance. Furthermore, studies $[10,20,25,30]$ also confirm that the energy absorption of foams and honeycombs increases as their densities increase. Higher density fillers could lead to bulky and heavy designs which should be avoided in real-world applications. Therefore, the study in this paper focuses on honeycomb filled tubes, targeting towards optimisation due to a generally higher energy absorption to weight ratio.

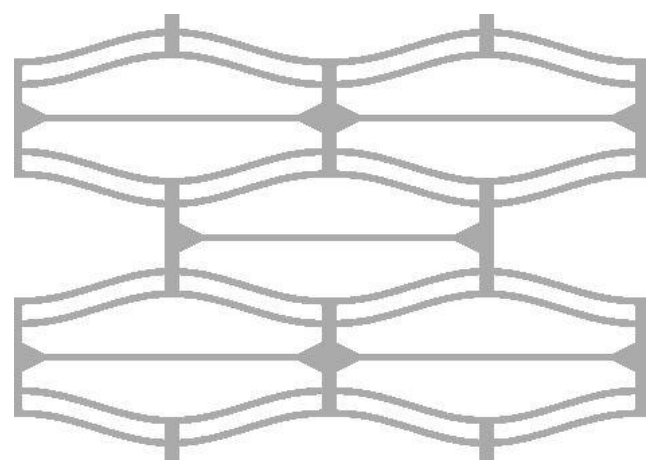

Figure 1. Negative stiffness honeycomb [9]

Inspired by the honeycomb design a new Negative Stiffness Honeycomb (NSH) structure shown in Figure 1 has been developed recently by Correa et al. [9]. Unlike other energy absorbers it is capable of providing repeated protection from multiple impacts by recovering its original shape each time after impact. According to experimental results [9] this design shows a combination of recoverable energy absorption and high initial stiffness. This highly engineered breakthrough design can withstand both blunt and ballistic impact, demonstrating a better performance than conventional honeycombs. The structure is required to be loaded laterally in order to retain its energy recoverable ability. When compared to the general energy absorption capability of thin walled structures, which is the highest when loaded axially [18], the energy absorption ability of an NSH structure is relatively low. Its low energy absorbing performance is partly due to the material used for the structure, which is Nylon 11 and for which the strength is significantly lower than for aluminium alloy. Despite its weaker energy absorption, the application of such a structure as an energy absorber in vehicles has very high potential as it can absorb energy repeatedly and be reused after collision. Furthermore, its performance can be improved by using the shape memory effect, and ferroelectric and magnetostrictive alloys. These modifications maintain its ability to provide recovery whilst increasing the strength to a level similar to that of conventional aluminium alloy $[6,31,32,33]$. Further improvement can also be gained by optimising the cell dimensions according to the impact conditions.

Due to recent advancements in computing power the majority of studies devoted to the behaviour of energy absorbing structures under a variety of different impact loadings are performed using finite element analysis (FEA) [9,10,20,24,25].

Therefore, the work reported in this paper is an attempt to create a novel passive safety tubular element represented by a hybrid energy absorbing structure combining the advantages of the negative stiffness honeycomb [9] and the optimised honeycomb filled tube [10]. It is intended that the NSH filled tubular structure will keep a high energy 
absorption to weight ratio, but will be enhanced with a capability for providing repeated protection from multiple impacts due to the recovery property of NSH. Thus a finite element (FE) model is created in order to investigate the behaviour of $\mathrm{NSH}$, an empty tube, and a hybrid structure under crash test conditions defined by the Insurance Institute of Highway Safety [34]. The novel hybrid structure is intended to be in a bumper-crush can design in which recoverable elements are integrated in both the bumper beam and crush can for mild collision, whilst traditional structural energy absorbers could be retrained for more severe collisions. The principal parameters such as density, yield strength, dimensions, elastic modulus, Poisson's ratio and ultimate strength are adopted following the studies $[9,10]$ for the purpose of verification and demonstration of consistency of results.

\section{The novel design description and optimisation}

The analysis of the energy absorbing properties of crush cans in the literature commonly invokes various crash parameters such as the specific energy absorption (SEA), the crash load efficiency (CLE), and the mean crushing force (MCF). In general SEA is defined as the energy absorbed per unit mass [35]:

$$
\operatorname{SEA}(d)=\frac{E A(d)}{m}
$$

where $m$ is given as the mass of the deforming structure, and $E A$ represents the total energy absorbed.

Since the honeycomb structure is considered to be one of the most efficient in terms of its level of energy absorption, an extensive investigation of various honeycomb structures has been carried out in order to optimise the shape, material and energy absorption ability. This was necessary in order to be able to improve the energy absorbing ability of bumper and crush can applications for the novel design under development. As a result of this comprehensive literature analysis it was found to be possible to compose a table summarising the performance of different types of honeycomb structures.

Table 1. SEA for the variety of honeycombs available $[9,23,24,25]$

\begin{tabular}{|l|l|l|l|l|}
\hline Design & Name & $\begin{array}{l}\text { SEA } \\
(\mathrm{J} / \mathrm{kg})\end{array}$ & $\begin{array}{l}\text { Num. of } \\
\text { cells per } m^{2}\end{array}$ & $\begin{array}{l}\text { Loading } \\
\text { method }\end{array}$ \\
\hline \\
\hline
\end{tabular}




\begin{tabular}{|l|l|l|l|l|}
\hline & $\begin{array}{l}\text { Nomex ECA honeycomb- } \\
\text { filled aluminium tube }\end{array}$ & 16,670 & 112,765 & Axial loading \\
\hline & $\begin{array}{l}\text { Honeycomb-filled single } \\
\text { hexagonal tube }\end{array}$ & $14,138.7$ & 24,056 & Axial loading \\
\hline & $\begin{array}{l}\text { Honeycomb-filled bi- } \\
\text { tubular hexagonal tube }\end{array}$ & $13,407.6$ & 24,056 & Axial loading \\
\hline & $\begin{array}{l}\text { Regular hexagonal } \\
\text { honeycomb }\end{array}$ & 995.9 & 7425 & Lateral loading \\
\hline $\begin{array}{l}\text { Negative stiffness (NS) } \\
\text { honeycomb }\end{array}$ & 889.6 & 881 & Lateral loading \\
\hline
\end{tabular}

The data presented in Table 1 confirms that the energy absorption capacity of honeycomb structures is much higher under axial loading as compared to lateral loading in comparison with results obtained by Said el. [26]. Besides this, evidence has been found for extraordinary performance in terms of weight to energy absorption ratio in reinforced, axially-loaded honeycombs. It also should be noted that the specific energy absorption, SEA, of honeycomb structures increases as the density of the cells increases. It can be seen that a Nomex ECA honeycomb [23] has a dense cell arrangement, and that both the aluminium tube and the honeycomb are not optimised for impact, resulting in a low SEA. On the other hand, high SEA values obtained from an optimised honeycomb filled aluminium tube in [10] can be achieved due to optimisation of both the aluminium tube and the honeycomb filling, and tailored for certain crash conditions. The same trend exists for both laterally loaded models where the NS honeycomb is optimised, and where the regular hexagonal honeycomb is not optimised. Therefore the optimisation process is crucial for the design of an efficient crash absorber. Optimisation is typically performed using a multi design objective (MDO) procedure [45]. It has been applied to maximise the absorbed energy and the specific absorbed energy of the energy absorbing structures subjected to axial impact force by altering structural dimensions. A genetic algorithm from [46] is then applied to solve the MDO problem in every sub problem created using D-optimal design of experiments and the response surface approximation method (RSM). This determines the optimum tube geometry that absorbs maximum energy with a minimum weight. Within the MDO procedure, D-optimal design of experiments and the response surface approximation method (RSM) have been used to construct the subproblems.

In terms of the shape, the hexagonal filled tubes developed in Yin el. [24] demonstrate higher SEA due to their honeycomb filler and have lower weight when compared to the hexagonal bi-tubular honeycomb design. 
It should also be pointed out that the deformation of NS honeycomb (Table 1) without plastic deformation shows a much lower SEA value than in other designs. This is largely due to its loading method and the material used. Nevertheless, and despite its low specific energy absorption value, it can absorb energy from multiple impacts in the event of collision. With its recovery ability this design is potentially suitable for integration into a car bumper. Thus, it has been selected for further investigation in this paper.

Optimised tubes filled with honeycomb demonstrate the highest ratio of energy absorption to weight and NS honeycombs and are suitable for implementation in optimised filled tubes under high impact load. Thus, further investigation is carried out on the development of the concept of a tubular structure filled with NS honeycomb (Fig.2).

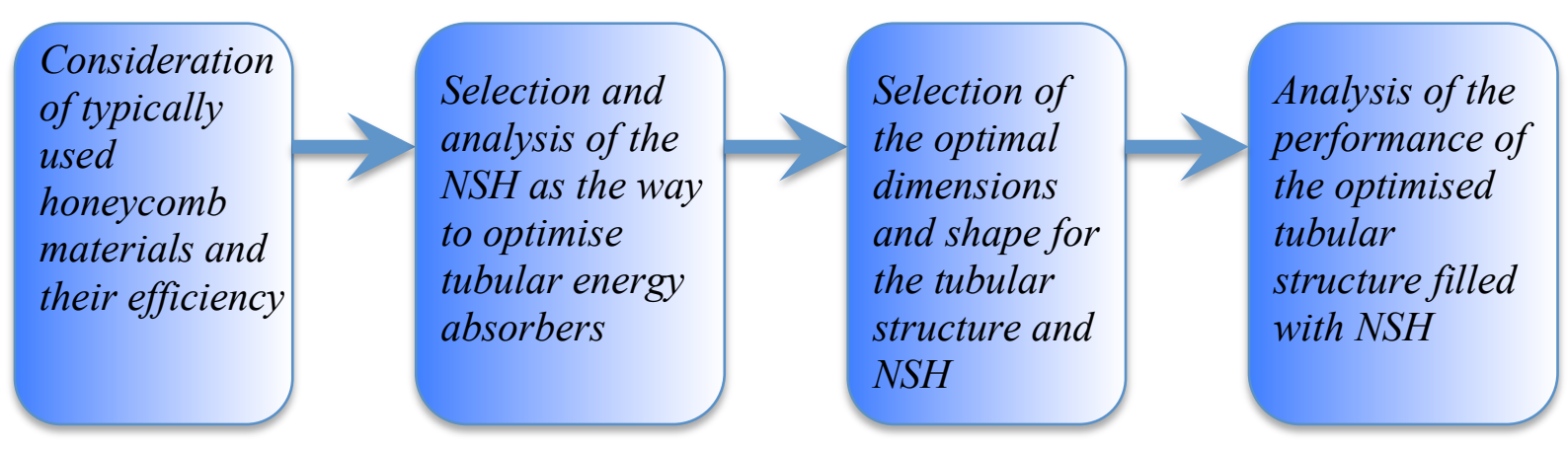

Figure 2. Optimisation process of a tubular structure applying NSH

\section{Derivation of the model for NS honeycomb}

According to [36], 50\% of small cars perform poorly in small overlap frontal tests. As small cars are commonly found on British roads their energy absorbers clearly need careful consideration of passive safety performance in order to improve test ratings in order to keep up with the Euro NCAP standard. Therefore, the impact scenario in this investigation is based on the crash test specified by IIHS [34]. Figure 3 (a) and (b) show the offset condition and dimensions of the impact barrier for the crash test.

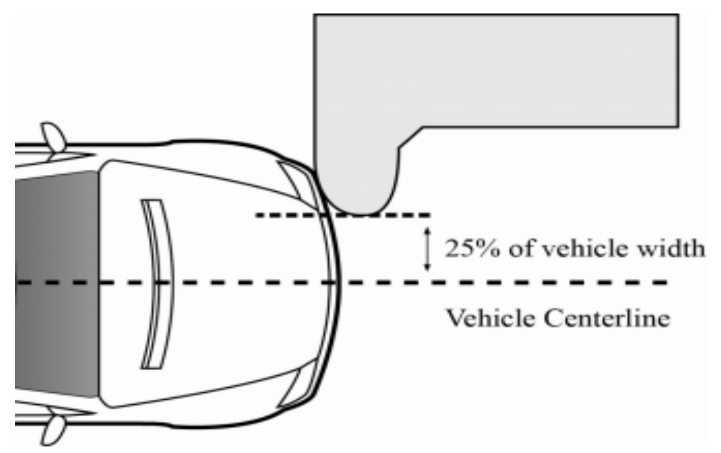

(a)

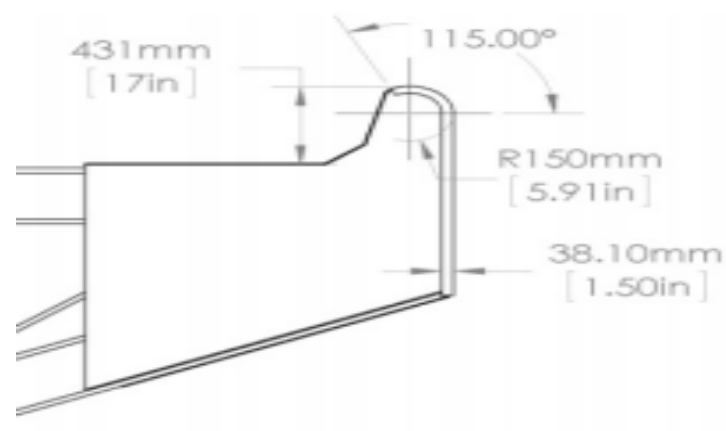

(b) 
Figure 3. (a) 25\% offset condition [7], (b) Impact barrier dimension [7]

The energy absorbers are commonly located at a point approximately $25 \%$ off the centreline of the vehicle, as shown in Fig. 3. Comparing Figs. 3 (a) and (b), the rounded edge of the impact barrier in Fig.3 (b) can be assumed to strike directly onto the energy absorbers.

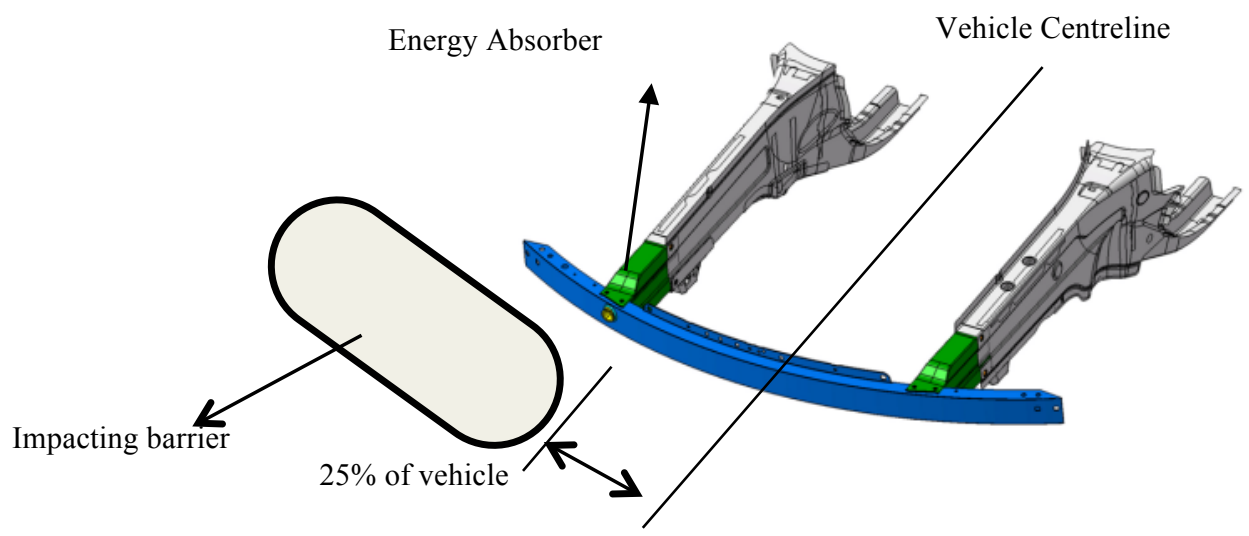

Figure 4. Location of the energy absorbers and impact barrier [7]

To simplify the modelling and analysis processes approximations have to be made to the frame of reference for simulation purposes. The rounded edge of the impact barrier can be modelled as a $0.3 \mathrm{~m}$ diameter sphere striking directly onto the energy absorber at a constant velocity. Accounting for inertial effects the sphere will carry a mass of $1205 \mathrm{~kg}$, which is at a level similar to that of a family hatchback car such as the Mk7 Volkswagen Golf manufactured by Volkswagen AG [37]. In addition, the energy absorber is clamped and stationary, with its fixed support at the bottom.

Crashworthiness of energy absorbers has been studied under different collision velocities. In order to simulate a more representative configuration and therefore obtain more realistic results, structures are tested according to different speed limits operating on British roads [38], and are presented in Table 2.

Table 2. British road speed limit for cars [38]

\begin{tabular}{|l|l|l|}
\hline Velocity $(\mathbf{m} / \mathbf{s})$ & Velocity $(\mathbf{k m} / \mathbf{h})$ & Type of road \\
\hline 13.4 & 48.3 & Built up areas \\
\hline 26.8 & 96.6 & Single carriageway \\
\hline 31.3 & 112.7 & Motorway \\
\hline
\end{tabular}

The European Aluminium Association [39] has stated that passive crash protection, such as encountered in car bumpers and crush cans, has different priorities according to the impact speed of the vehicle. For a collision speed under $15 \mathrm{~km} / \mathrm{h}$ an energy absorber should require a minimum repair cost, whilst occupant protection is prioritised for collisions above $40 \mathrm{~km} / \mathrm{h}$. Thus in this paper an investigation on a 14.8 $\mathrm{km} / \mathrm{h}$ collision has been undertaken on the NS honeycomb system as it then possesses the ability to recover and will perform better in term of minimisation of repair costs. 
An investigation into the performance of novel energy absorbers under impact has been undertaken by using the ANSYS Workbench 16.1 environment and applying the Explicit Dynamics Solution software since this provides a more accurate assessment by taking into account the shock waves propagating through the structure, and also the inertial effects.

This simulation demonstrates the crashworthiness of both the Negative Stiffness honeycomb on its own, and a circular tube filled with NS honeycomb, under an impact similar to that of a $25 \%$ overlap vehicle crash.

The geometry chosen for the simulation has been adopted from the research work carried out in [9] (Fig. 5(a) - in mm). Using the dimensions stated therein, a NS honeycomb FEM has been developed using the Solidworks 2014 3D CAD design software, as shown in Fig.5(b). The thickness of the model was extruded to be $12.7 \times 10^{-}$ ${ }^{3} \mathrm{~m}$. The model was then analysed using the ANSYS Static Structural analysis software.
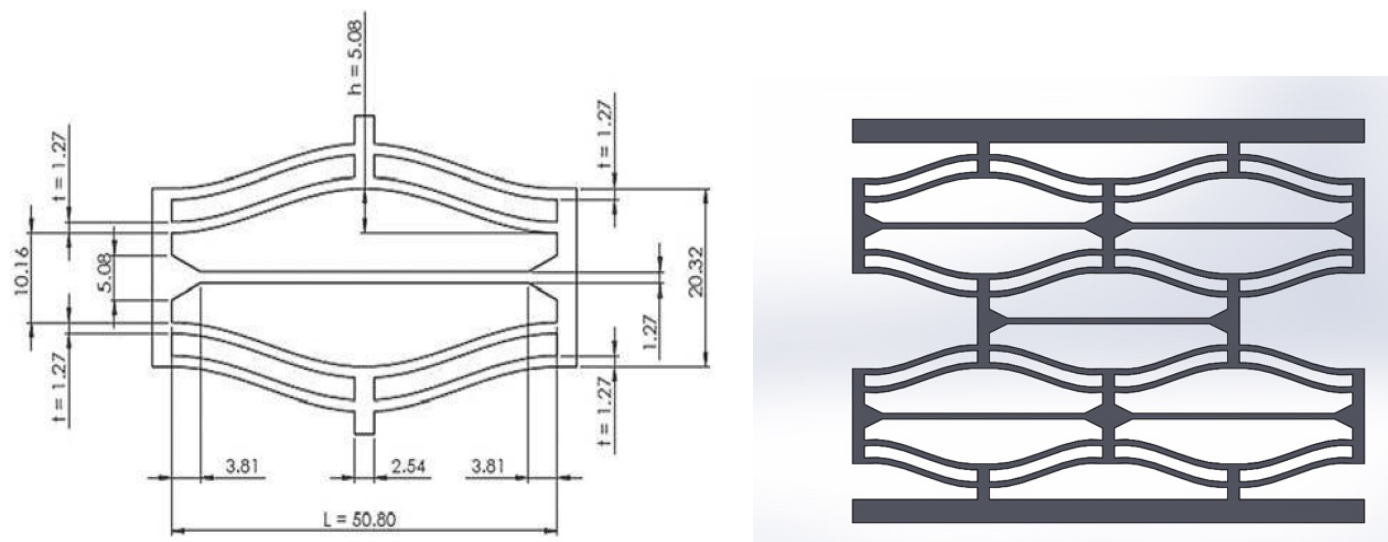

Figure 5(a). NS honeycomb dimensions [9], (b) NS honeycomb model

\section{Verification and validation of the model developed}

Following the approach discussed in [40] verification has been carried out for the NS honeycomb model according to the criteria given by [9]. In order to verify the accuracy of the model created a comparison of the energy absorption ability between the numerical solutions and the experimental data was performed.

Base on [9] the loading can be characterised as quasi-static, and compression of the structure can be performed vertically at a rate of $5 \times 10^{-3} \mathrm{~m} / \mathrm{min}$. Due to this slow compression rate the inertial effects in the simulation can be neglected. Therefore the validation has been carried out within the ANSYS 16.1 Static Structural software environment by assuming the problem to be dominated by a single static load. Nylon 11 of density $\rho$ of $1040 \mathrm{~kg} / \mathrm{m}^{3}$, Poisson's ratio of 0.33 and Young's modulus, E of $1582 \mathrm{MPa}$ is the material chosen for the validation process. An element size of $0.015 \mathrm{~m}$ has been found to be sufficient for the study and the boundary conditions were set to be identical to the study in [9], where one side is fixed while the other is roller supported to constrain the movement of the vertical beams. A ramped displacement of $5 \times 10^{-3} \mathrm{~m}$ is imposed evenly on the top surface of the structure for 60 seconds. Figure 6 shows the detailed boundary and loading conditions on the NS honeycomb. 


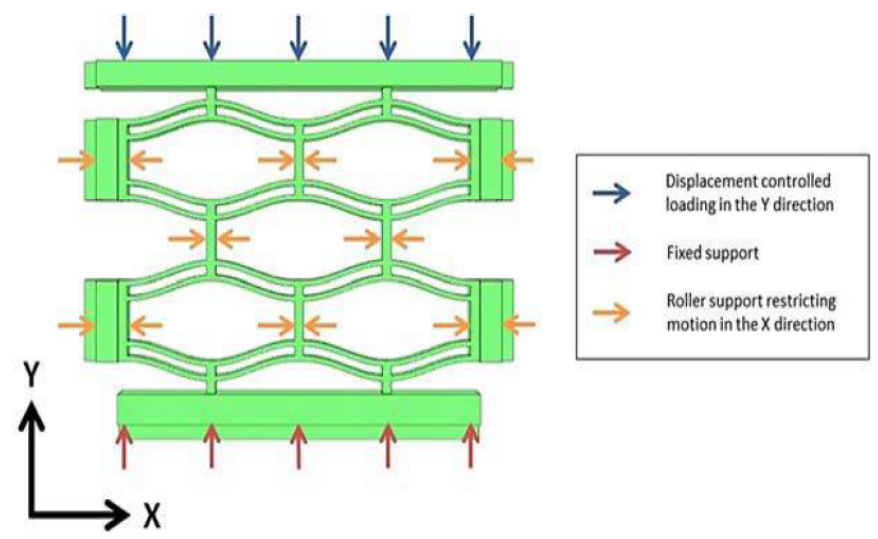

Figure 6. Loading and boundary conditions for the numerical analysis

A force-displacement graph was plotted using the data collected from the simulation of the model, and this was compared with the FEA results generated (Figs. 7 (a) and (b)). The part of the graphs where the displacement was beyond $0.05 \mathrm{~m}$ was neglected for the justification process. This was because of the limitations of the Static Structural software for which the buckling of the structure could not be considered.

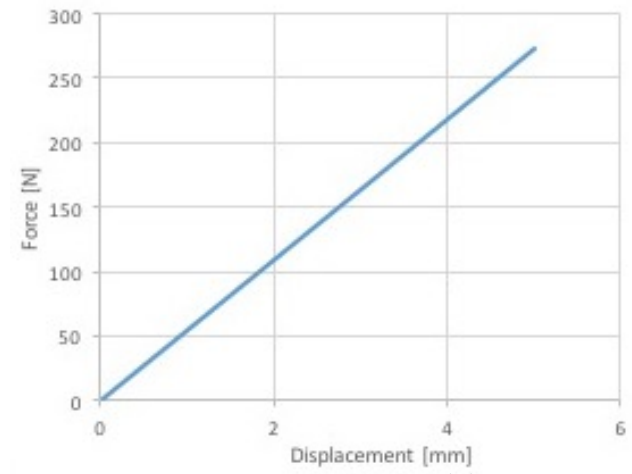

(a)

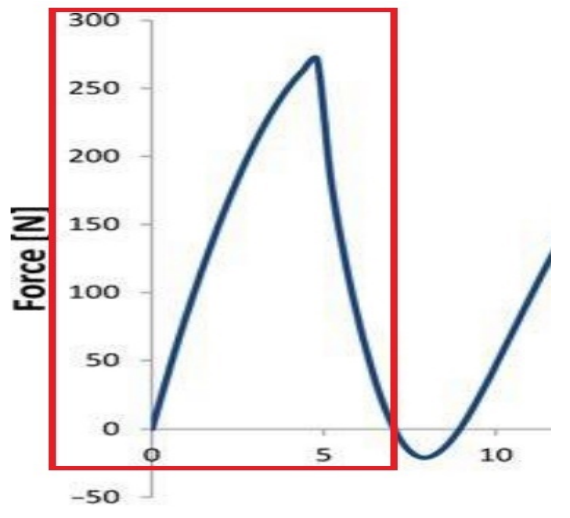

(b) Displacement $[\mathrm{mm}]$

Figure 7. Force displacement graph of (a) the numerical simulation and (b) the model developed in [9]

As can be noted from the results the force exerted on the numerically simulated structure, allowing for the designated displacement of $5 \times 10^{-3} \mathrm{~m}$, is at the rate of $275 \mathrm{~N}$. In addition, the trend of the force increment plotted against the vertical displacement shows an increase and is similar in both, and given in Figs 7 (a) and (b). The results for the energy absorbed in both cases, for the $5 \times 10^{-3} \mathrm{~m}$ displacement, are presented in Table 3. 
Table 3. Energy absorbed within the model developed and presented in [10]

\begin{tabular}{|l|l|}
\hline Model & Energy Absorbed (J) \\
\hline FE model developed & 0.683 \\
\hline The model in [9] & 0.688 \\
\hline
\end{tabular}

The difference in energy absorption ability may be affected by the limitations of the Static Structural software and because the FE model was developed under the assumption that the structure does not buckle and that it deforms as described in the experiment in [9]. Despite this small discrepancy the results confirm that the model is valid for further evaluation.

\section{Development of the finite element model of the optimised NS honeycomb}

A finite element model for the optimised NS honeycomb has been created to improve the structural performance of the honeycomb in terms of its energy absorbing capability. By applying finite element analysis an evaluation and improvement by $45 \%$ in energy absorption capability over the initial model has been achieved. Following [41] this improvement has been obtained based on changes of the dimensions of the structure, which is different from, for example, the hexagonal honeycomb, where optimisation is done by relative density alteration. Therefore, in the further discussion a finite element model for an optimised NS, characterised by the new dimensions stated in Table 4 and Fig. 8, is applied.

Table 4. Dimensions of the optimised NS honeycomb based on [41]

\begin{tabular}{|l|l|l|l|}
\hline Parameter & Symbol & Original Value (m) & Optimized value (m) \\
\hline Length & L & 0.00508 & 0.00412 \\
\hline Thickness & t & 0.00127 & 0.00114 \\
\hline Apex height & h & 0.00508 & 0.00508 \\
\hline Width & b & 0.00127 & 0.00135 \\
\hline
\end{tabular}




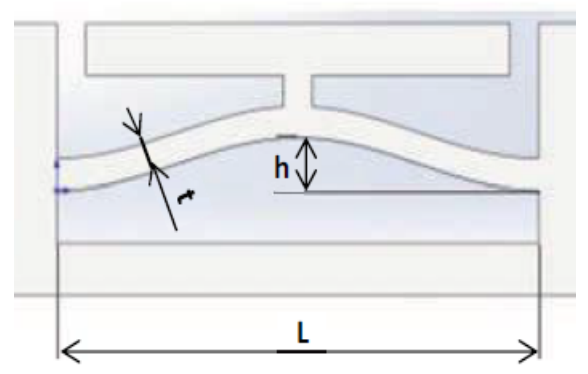

Figure 8. Symbolic representation of the optimisation performed for the NS honeycomb [41]

In order to validate the finite element model developed for the new optimised structure, developed in [41], a force-displacement graph is presented in Fig. 9 in which a comparison of the performance of both the initial and optimised models can be seen.

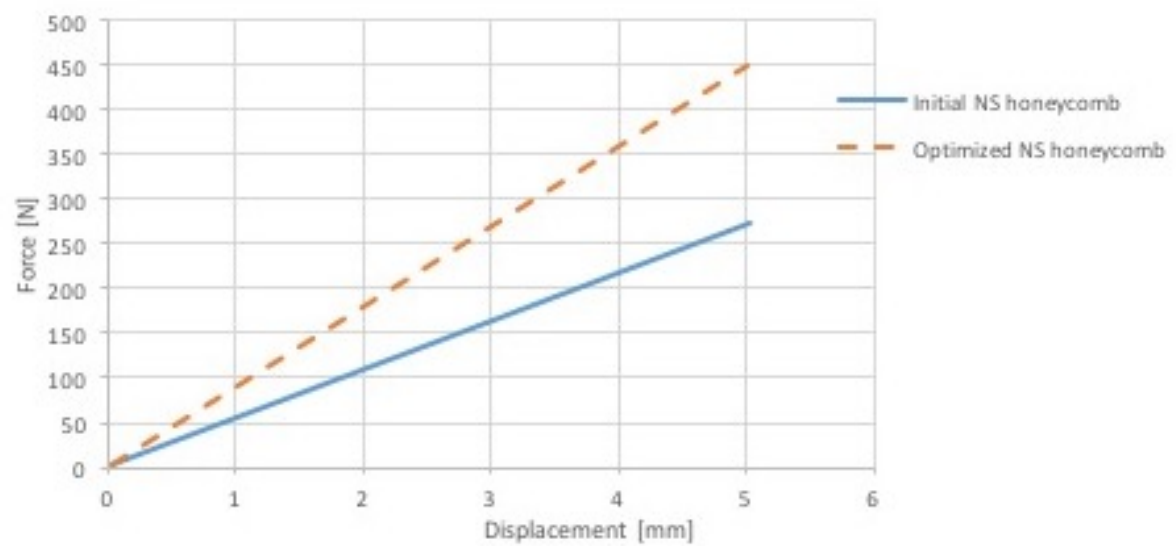

Figure 9. Force displacement behaviour of the initial (based on results in [41]) and optimised NS honeycomb

The graph in Fig. 9 shows that the optimised honeycomb suggested in [41], demonstrates a significantly improved energy absorbing ability. On the one hand the force required to deform the structure by $0.005 \mathrm{~m}$ has been increased from $275 \mathrm{~N}$ up to $450 \mathrm{~N}$. On the other hand the rate of force increment as the displacement increases is more rapid for the optimised honeycomb, resulting in greater energy absorption ability. Finally, the energy absorbed by the optimised model has increased by $64 \%$ as compared with the initial model, with a value of $1.121 \mathrm{~J}$. The optimised model is still characterised by the same trend as the original one subjected to the loading. The deformations generated within the initial and optimised NS honeycomb models are demonstrated in Figs. 10 (a) and (b) respectively. 


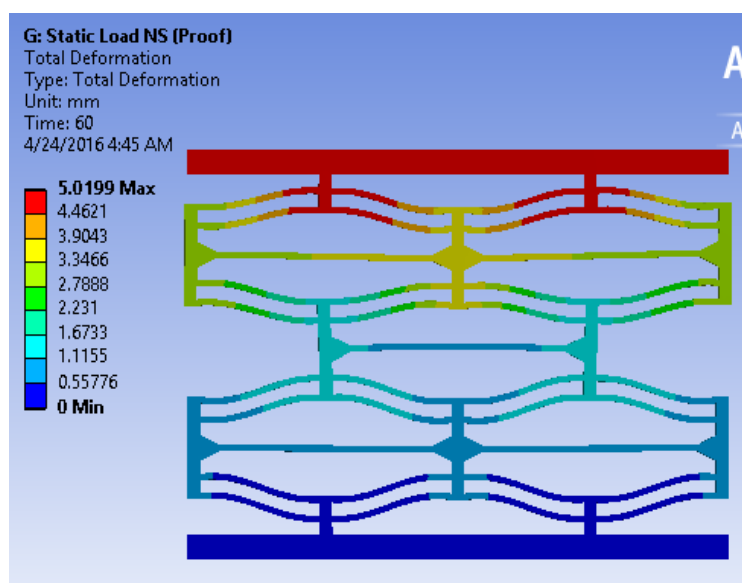

(a)

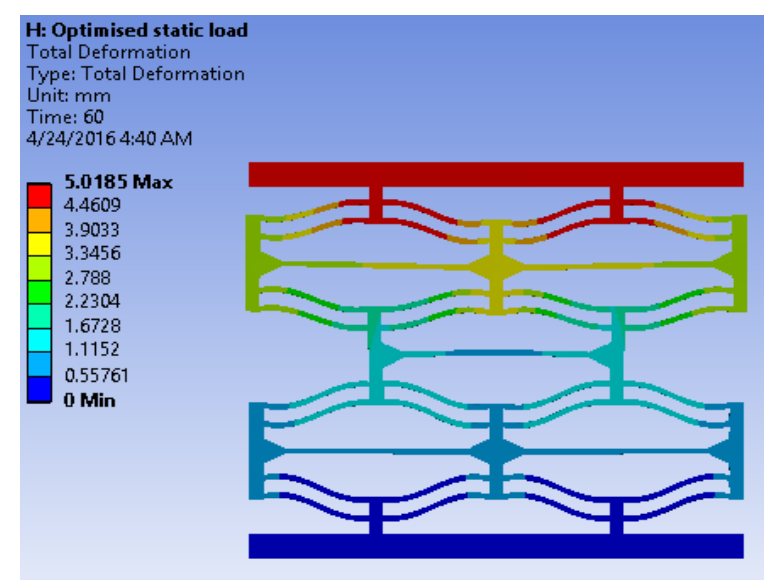

(b)

Figure 10. Deformation results for (a) initial model and (b) optimised model

\section{Simulation of a crash test by means of a drop ball test}

As described in Fig. 11 (a), a performance of the bumper beam was simulated as a three layered NS honeycomb structure undergoing a collision-like impact loading. The thickness of the honeycomb layers was increased from $0.00114 \mathrm{~m}$ up to $0.08 \mathrm{~m}$ to accommodate the design features and dimensions of a typical bumper beam.

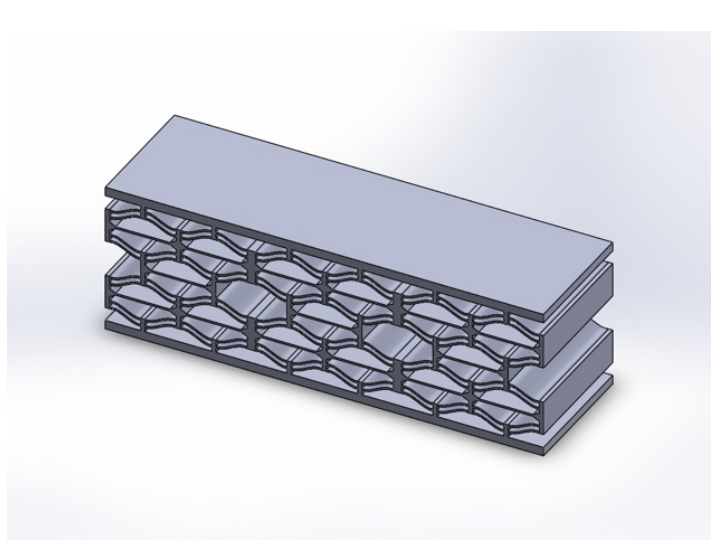

(a)

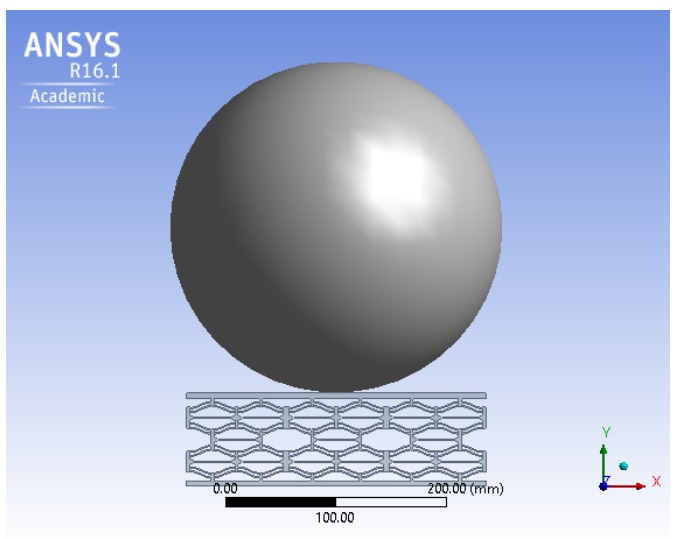

(b)

Figure 11. Finite element model adopted for the bumper beam impact test

The boundary conditions are defined as shown in Fig. 6, disregarding the application of the displacement on the top surface. This displacement was replaced by a sphere of diameter of $0.3 \mathrm{~m}$ impacting the structure at constant velocities of $14.8 \mathrm{~km} / \mathrm{h}$, $48.3 \mathrm{~km} / \mathrm{h}, 96.6 \mathrm{~km} / \mathrm{h}$ and $112.7 \mathrm{~km} / \mathrm{h}$ respectively. The mass of the sphere was chosen to be $1205 \mathrm{~kg}$ in order to reflect the inertia of a typical car (Fig.11 (b)). 
The material of the NS honeycomb was Nylon 11 of the properties mentioned in section 4. A mesh element size of $0.015 \mathrm{~m}$ was chosen for the NS honeycomb whereas the sphere was represented using a slightly larger mesh element of $0.002 \mathrm{~m}$. This was done to reduce unnecessary computational effort, and to consider only the behaviour of the NS honeycomb structure in detail. As stated in [9] a deformation which is beyond $40 \%$ of the honeycomb compression length will lead to densification, therefore the maximum deformation displacement was set to be $0.035 \mathrm{~m}$. Equation 2 was used to calculate the simulation end-time required for a $35 \times 10^{-3} \mathrm{~m}$ displacement, given that the simulation is time based.

$$
\text { End time }=\frac{d}{v}
$$

where $\mathrm{d}$ is the crushing distance, and $\mathrm{v}$ is the impact velocity of the impacting ball.

\section{Development of the finite element model for the novel NS honeycomb filled circular tube}

Taking into account the efficiency of circular tubes [17], the geometrical parameters of the circular tube chosen for the NS filler design were selected based on [10]. The model of the empty circular tube and then with a NS honeycomb filler was developed using the Solidworks 2014 3D CAD environment following the approach discussed above.

Using the manufacture's data [23], a NS honeycomb filler of strength of $0.896 \mathrm{MPa}$ was applied in order to achieve the necessary strengthening effect within the structure. The honeycomb cell size, $Q$ could be defined as $0.009525 \mathrm{~m}$ whereas the cell wall thickness, $t$ was given as $0.000381 \mathrm{~m}$. Figure 12 identifies these parameters. The recommended aluminium alloy type 5052 was assumed for optimum energy absorbing performance. The material properties of this alloy were obtained by utilising the CES Edupack 2014 software by Granta Material Intelligence [42] and are tabulated in Table 5.

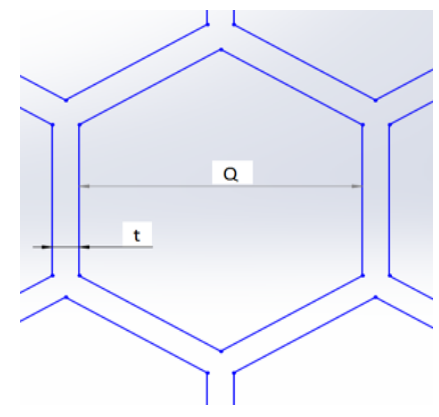

Figure 12. Characteristic parameters of the honeycomb filler 
Table 5. Material properties of aluminium alloys 5052 and 6060 [42]

\begin{tabular}{|l|l|l|l|}
\hline Material Properties & Unit & Aluminium 5052 & Aluminium 6060 \\
\hline Density, $\rho$ & $\mathrm{kg} / \mathrm{m}^{3}$ & 2680 & 2700 \\
\hline Young's modulus, $E$ & $\mathrm{GPa}$ & 70.3 & 70 \\
\hline Poisson's ratio & - & 0.33 & 0.33 \\
\hline Yield stress, $\sigma_{\mathrm{r}}$ & $\mathrm{MPa}$ & 89.6 & 231 \\
\hline Ultimate stress, $\sigma_{\text {uᄂт }}$ & $\mathrm{MPa}$ & 193 & 254 \\
\hline
\end{tabular}

The dimensions for the optimum energy absorbing cylinder were chosen to be $0.00205 \mathrm{~m}$ for the wall thickness $(T), 0.00307 \mathrm{~m}$ for the diameter $(D)$, and $0.12 \mathrm{~m}$ for the length $(L)$, and these figures were based on the work of [10]. It was also assumed that $60 \%$ of the total length would account for the deformation, therefore:

$$
L \times 0.6=L_{e}
$$

where $L_{e}$ is given as the effective length of deformation.

Following the approach described in [43] a thin shell model was developed capable of simulating the bending effects of the thin walled structure with more precision. Following [44], ANSYS 3D solid-shell elements, combining the benefits of both shell and solid elements, were chosen since they generally provide more accurate results in this sort of physical context with less computational requirements.

The model developed was validated through a comparison of the Explicit Dynamics finite element model with the experimental data presented in [10] (Fig. 13). The numerical simulation for the comparison was performed for a vertical impact at the top of the cylinder, filled with standard hexagonal honeycomb (aluminium 5052 from Hexcel composites [23] with filler strength of $0.896 \mathrm{MPa}$ ) assuming that a maximum load of $154 \mathrm{~kg}$ is dropped at a constant velocity of $12.5 \mathrm{~m} / \mathrm{s}$, and that a mesh of $0.015 \mathrm{~m}$ is deemed to be acceptable, and that the length of the tube is extruded at $0.03 \mathrm{~m}$ as opposed to $0.12 \mathrm{~m}$ as used in the experimental study in order to reduce the computational time required.

Failure as a result of tension and shearing force while loading was considered by applying the following failure criterion [23]:

$$
\left[\frac{\sigma}{\sigma_{\text {fail }}}\right]^{2}+\left[\frac{\tau}{\tau_{\text {fail }}}\right]^{2} \leq 1
$$

where $\sigma_{\text {fail }}$ represents the tensile strength and $\tau_{\text {fail }}$ represents the shear strength of the adhesive material. For this particular study values of $\sigma_{\text {fail }}=30 \mathrm{MPa}$ and $\tau_{\text {fail }}=5 \mathrm{MPa}$, respectively, were selected.

The boundary conditions assumed a clamp at the base of the structure and this enables the compression to occur when the impact is induced. Data collected from the finite element simulation and the experimental report is tabulated in Table 6. Despite the 
difference in tube length, both the experiment and the finite element models demonstrate extremely similar results in terms of specific energy absorption. Nevertheless, the experimental model has absorbed approximately 8 times more energy compared to the numerical model. This is mainly due to the much longer experimental crush length of $0.195 \mathrm{~m}$ as compared to just $0.016 \mathrm{~m}$ for the simulated model. In the model created it was not possible to simulate the exact length of tube used in the experiment due to the computational time restriction.

Table 6. Comparison of the energy absorbed and dimensions applied for experiment [10] and the finite element models

\begin{tabular}{|l|l|l|l|}
\hline Parameters & Units & Experimental & Numerical \\
\hline Honeycomb strength & $M P a$ & 0.896 & 0.896 \\
\hline Tube thickness, T & $m$ & 2.05 & 2.05 \\
\hline Diameter, D & $m$ & 0.0307 & 0.0307 \\
\hline Tube length, L & $m$ & 0.3 & 0.03 \\
\hline Crushed length & $m$ & 0.195 & 0.016 \\
\hline \hline Absorbed Energy, EA & $J$ & 8507 & 1085 \\
\hline Specific energy absorption, SEA & $\mathrm{J} / \mathrm{kg}$ & 71,728 & 71,846 \\
\hline
\end{tabular}

The physical deformations of the experiment and the finite element simulation are compared in Figs. 13 (a) and (b). It can be seen that both models have deformed in a similar folding pattern. This scenario occurs when structures are subjected to an even distribution of axial force on the loading surface, for which the maximum amount of energy may be absorbed.

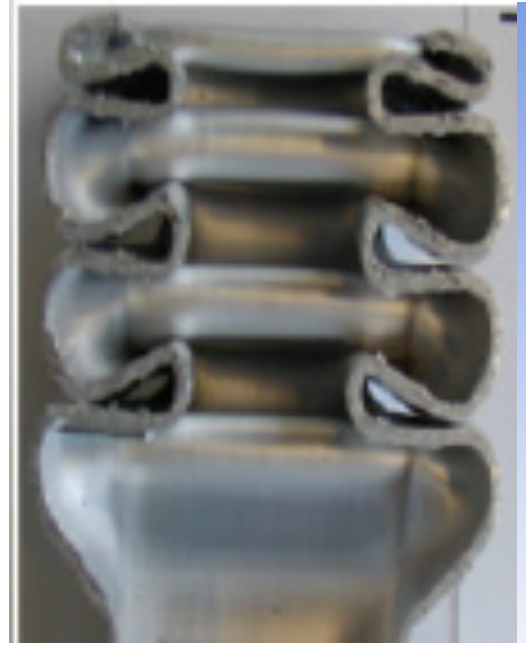

(a)

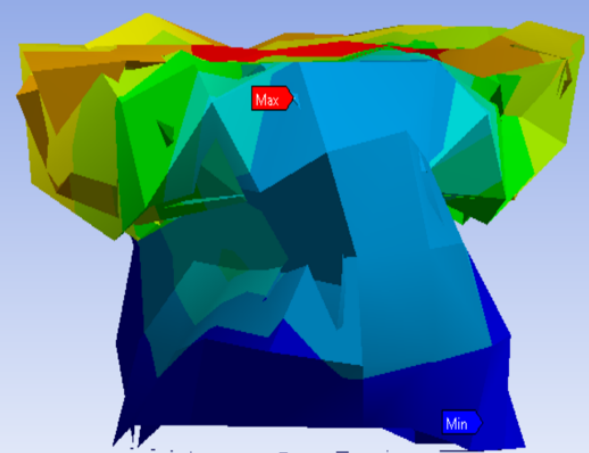

(b) 
Figure 13. (a) - Experimental [10] and (b) - finite element deformation for the Aluminium 6060 tube [10] filled with Aluminium 5052 honeycomb [23]

Figures 14 (a) and (b) shows the force-displacement graph of the finite element simulation and a comparison of both the filled and empty tubes with the first peak load 80 $\mathrm{kN}$ being similar for both the finite element and experimental cases. However, the mean crushing force for the simulated model oscillates around $65 \mathrm{kN}$ whereas the experimental model oscillates at only $40 \mathrm{kN}$. The higher mean crush force might be affected by the difference in material properties applied within each study. In contrast the non-filled tube has a lower peak crush force of $67 \mathrm{kN}$ and a mean crush force which fluctuates around 33 $\mathrm{kN}$. However, its energy absorption ability is still comparable to that of honeycomb filled structures due to its thicker tube wall and additional deformation length, as shown in Fig. 14(b). As the thicker tube wall has introduced some extra weight, it can be concluded that honeycomb filled structures are still superior in terms of the weight to energy absorption ratio.

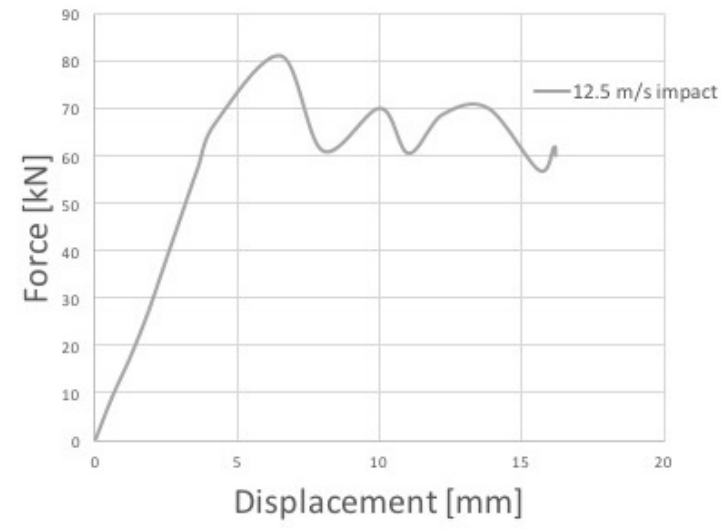

(a)

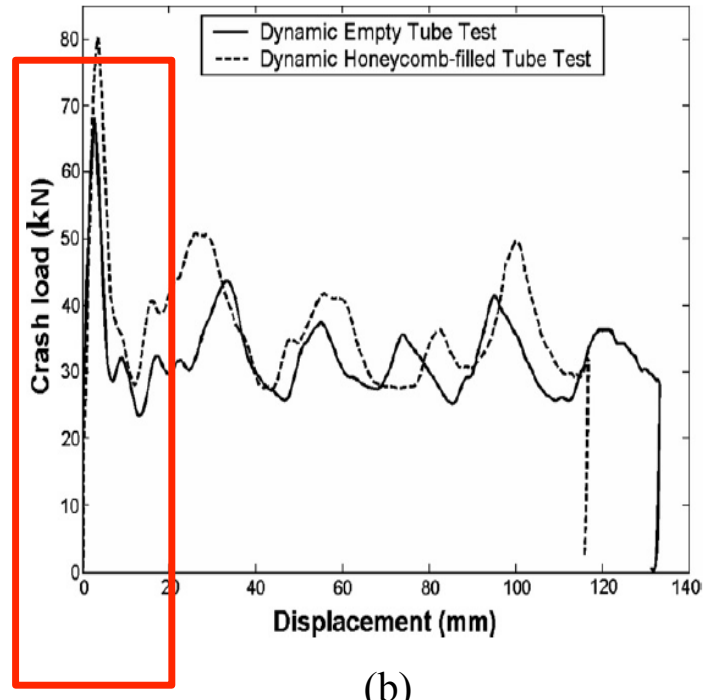

(b)

Figure 14. Results of (a) the finite element model of the honeycomb filled tube results and (b) experimental tests of both the honeycomb-filled and empty tubes

[10]

In order to investigate the energy absorption ability of the structure during the impact a drop ball impact analysis has been performed. The length of both the tube and the honeycomb filler are extended from $0.03 \mathrm{~m}$ to $0.05 \mathrm{~m}$ to analyse their crumpling effect. The impact on the honeycomb-filled tube and the empty tube of the same dimensions has been simulated. Both models were set up using Explicit Dynamics and exploiting the geometrical dimensions and boundary conditions discussed in the previous section. A ball of diameter $0.3 \mathrm{~m}$ was modelled and positioned axially above the structure. The ball was set to travel and to impact on the energy absorbing tube eccentrically at constant velocities of $14.8 \mathrm{~km} / \mathrm{h}, 48.3 \mathrm{~km} / \mathrm{h}, 96.6 \mathrm{~km} / \mathrm{h}$ and $112.7 \mathrm{~km} / \mathrm{h}$ respectively. Figure 15 demonstrates the physical arrangement of the impact ball and the energy absorbing structure. 


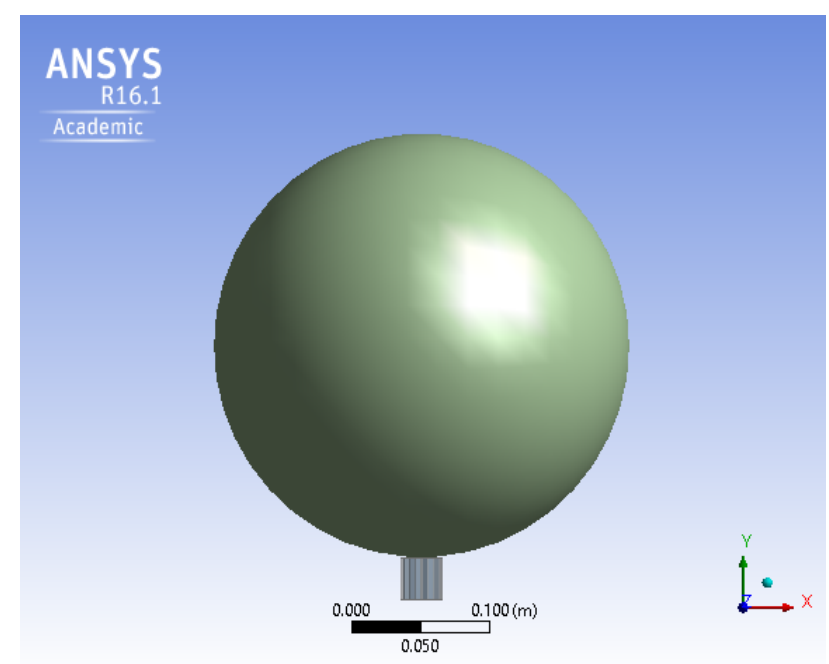

Figure 15. Physical arrangement of the impact ball and the honeycomb-filled tube

\section{Energy absorption analysis}

First of all, it is necessary to consider the energy absorption performance of the NS honeycomb, obtained from the different impact loading simulations using the finite element model.

Table 7. Energy absorption capacity of the NS honeycomb

\begin{tabular}{|l|l|l|}
\hline Impact velocity $(\mathrm{km} / \mathrm{h})$ & Energy absorbed $(\mathrm{J})$ & Specific energy absorption $(\mathrm{J} / \mathrm{kg})$ \\
\hline 14.8 & 2.972 & 4.951 \\
\hline 48.3 & 0.318 & 0.530 \\
\hline 96.6 & 0.195 & 0.324 \\
\hline 112.7 & 0.191 & 0.319 \\
\hline
\end{tabular}

As can be seen from the table the energy absorbing performance of the structure decreases as the impact velocity increases. The energy absorption (EA) drops significantly by $89 \%$ as the impact velocity increases from $14.8 \mathrm{~km} / \mathrm{h}$ up to $48.3 \mathrm{~km} / \mathrm{h}$. However, the EA performance decreases gradually when the velocity continues to rise from $48.3 \mathrm{~km} / \mathrm{h}$ up to $96.6 \mathrm{~km} / \mathrm{h}$. Therefore, the rate of decrease in the EA appears to have an exponentially decaying characteristic. Figure 16 demonstrates the relationship between specific energy absorption and impact velocity on the structure. 


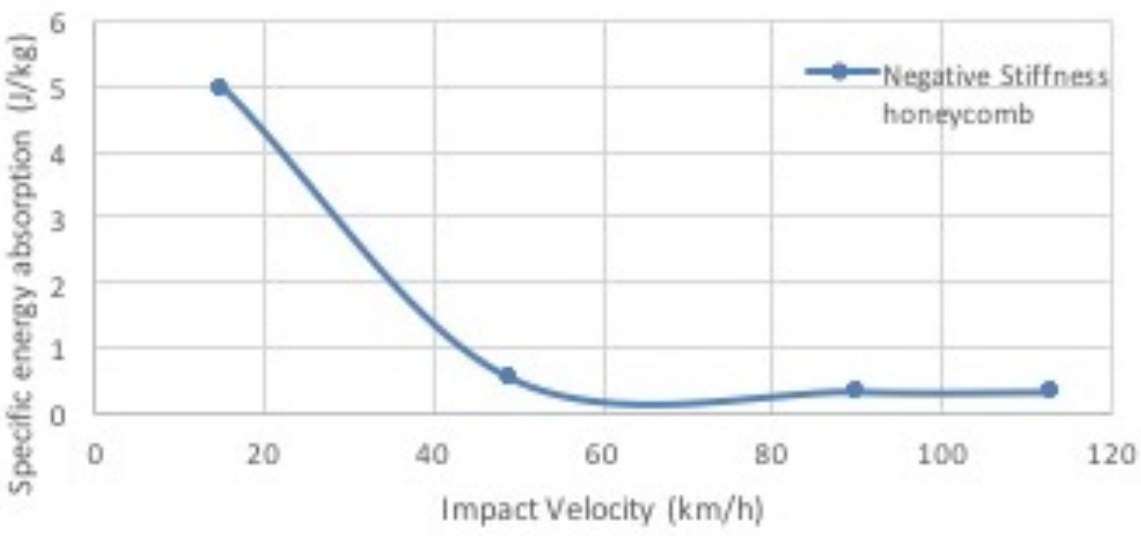

Figure 16. Specific energy absorption versus impact velocity for the NS honeycomb

Further investigation of the EA behaviour of the NS honeycomb is undertaken by analysing the relationship between applied force and deformation. Figures 17 (a) and (b) show the force-displacement graph for a $14.8 \mathrm{~km} / \mathrm{h}$ impact and also a $48.3 \mathrm{~km} / \mathrm{h}$ impact.

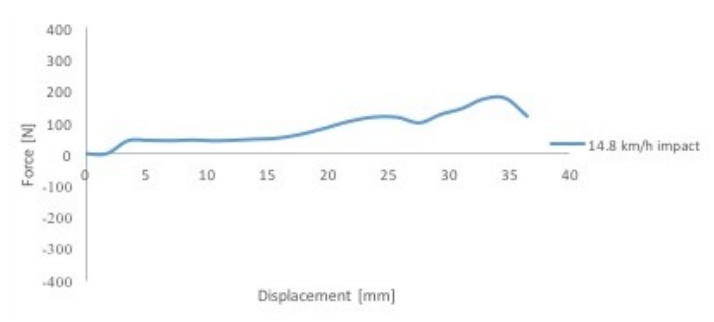

(a)

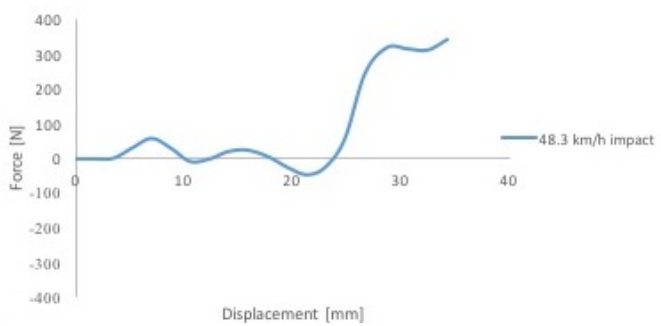

(b)

Figure 17. Force-displacement graph for (a) $14.8 \mathrm{~km} / \mathrm{h}$ and (b) $48.3 \mathrm{~km} / \mathrm{h}$ impact loading

From Fig. 17 it can be seen that the force exerted on the structure rises as the deformation increases. There is deformation and absorption of energy throughout the impact. The low initiation force proves that the structure is suitable for application in low speed collisions. The slight drop in force at approximately $0.027 \mathrm{~m}$ indicates a buckling of the beam within the structure due to its recovery ability. The force applied on the structure then continues to rise, and peaks at $178 \mathrm{~N}$ resulting in considerable energy absorbing performance. However the force starts to decrease as the deformation persists after the peak. This indicates that the Negative Stiffness honeycomb continue deforming due to inertia; and without absorbing the impact force. For the $48.3 \mathrm{~km} / \mathrm{h}$ impact the peak crushing force occurs at only $58 \mathrm{~N}$, which is significantly lower than that for the 14.8 $\mathrm{km} / \mathrm{h}$ impact. The energy absorption process stops at $0.018 \mathrm{~m}$ and this is where the negative force starts. This explains the dramatic drop in energy absorption when compared to that for the $14.8 \mathrm{~km} / \mathrm{h}$ impact. The negative displacement shown in Fig. 17 indicates that the structure tends to exert kinetic energy in a manner that opposes the 
applied force. In other word, the honeycomb attempts to bounce the impacting object and to oppose the direction of crushing like a spring. The results for $96.6 \mathrm{~km} / \mathrm{h}$ and 112.7 $\mathrm{km} / \mathrm{h}$ are shown in the energy absorption graphs of Figs. 18. In a manner similar to that of Fig. 17, the graphs reveal behaviour that is extremely similar for the higher impact force case.

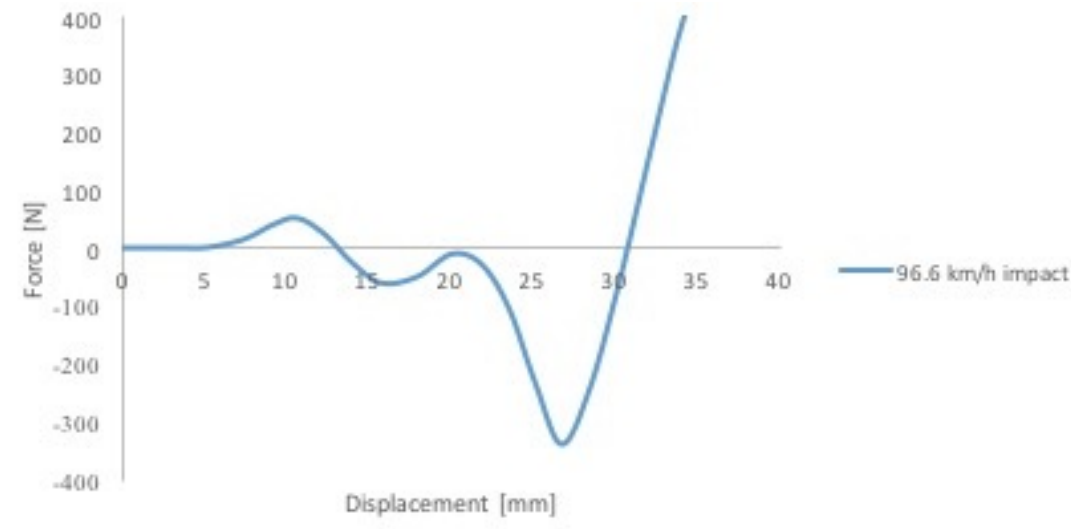

(a)

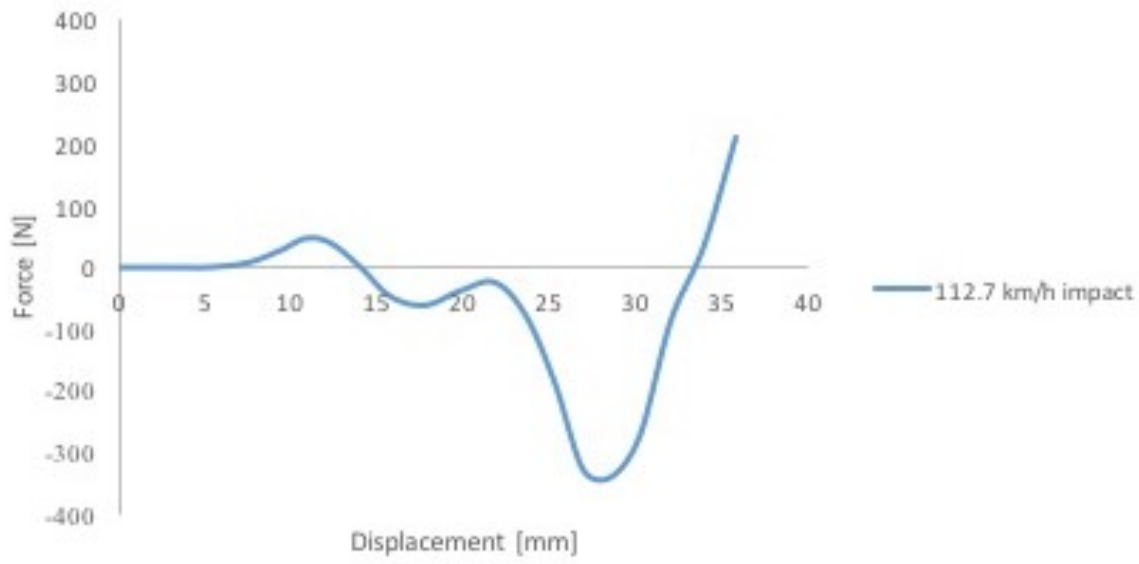

(b)

Figure 18. Force-displacement under impact at the speed of (a) $96.6 \mathrm{~km} / \mathrm{h}$ and (b) 112.7 $\mathrm{km} / \mathrm{h}$

To facilitate study of the energy absorption capabilities of the NS honeycomb filled tubes the finite element model is used for both the honeycomb-filled and non-filled tubes and the results are recorded in the force-displacement graphs of. Figure 19 where comparisons of both structures under impact velocities of $14.8 \mathrm{~km} / \mathrm{h}, 48.3 \mathrm{~km} / \mathrm{h}, 96.6$ $\mathrm{km} / \mathrm{h}$ and $112.7 \mathrm{~km} / \mathrm{h}$ can be made. 

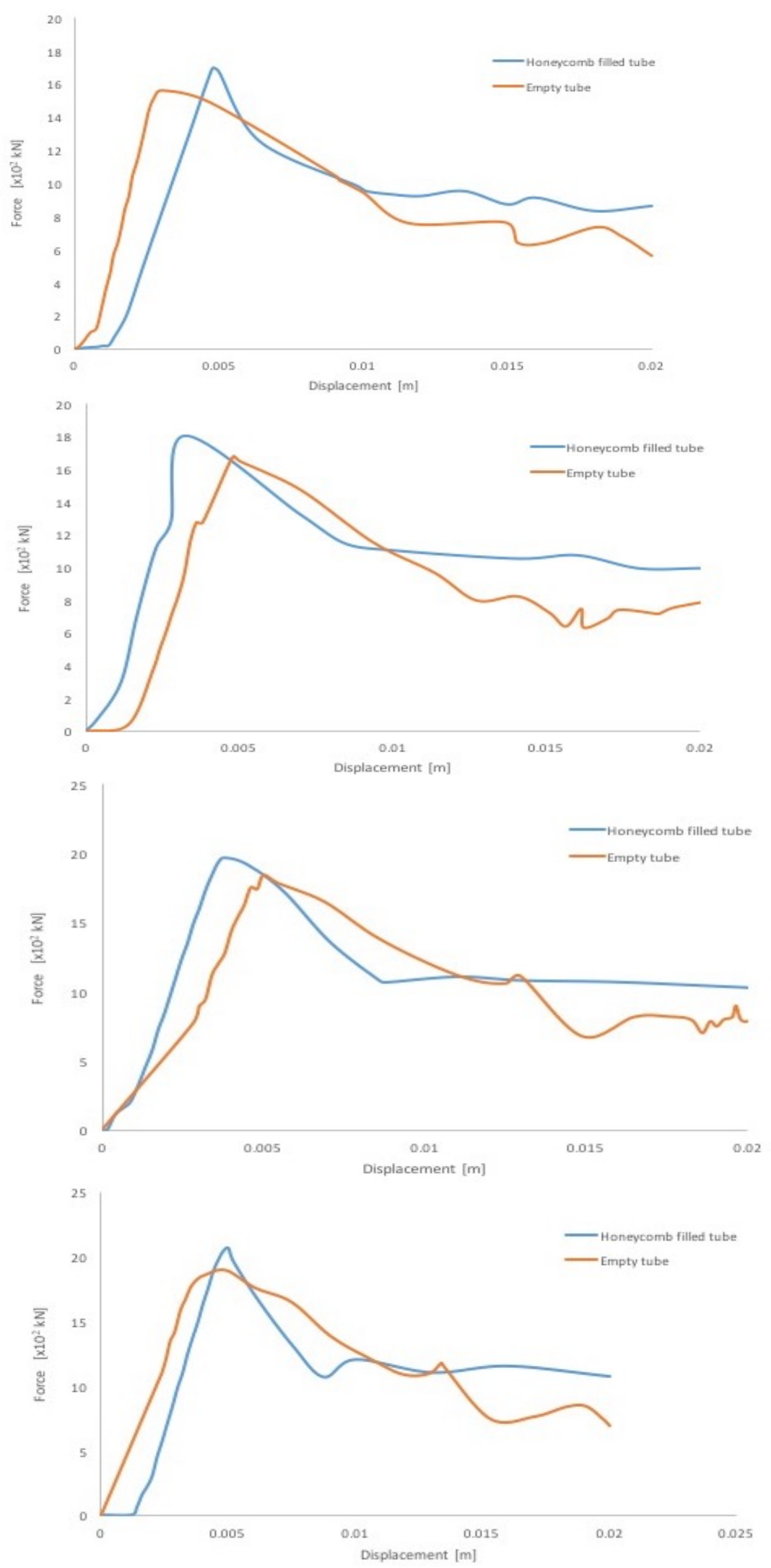

Figure 19. Comparison of NS honeycomb-filled and empty tubes at different speeds 
It can be noted in Fig. 19 that both the empty and the filled structures show similar behaviour under all the impact conditions tested. In general, the honeycomb-filled tubes tend to display a higher peak crushing force and mean crushing force when compared with the empty tubes. Therefore, the honeycomb-filled tubes do seem able to absorb significantly more energy than the empty tube. The requirement of a higher initial force for initiation of the crumpling effect is the only down-side of the honeycomb-filled tube. The results are further analysed in terms of the SEA.

Table 8. NS Honeycomb-filled and empty tube energy absorption data

\begin{tabular}{|l|l|l|l|}
\hline \multicolumn{2}{|l|}{ NS Honeycomb filled } & \multicolumn{2}{l|}{ Empty tube } \\
\hline Velocity $(\mathrm{km} / \mathrm{h})$ & SEA $(\mathrm{J} / \mathrm{kg})$ & Velocity $(\mathrm{km} / \mathrm{h})$ & SEA $(\mathrm{J} / \mathrm{kg})$ \\
\hline 14.8 & 988073 & 14.8 & 942377 \\
\hline 48.3 & 1100043 & 48.3 & 967348 \\
\hline 96.6 & 1150437 & 96.6 & 1075975 \\
\hline 112.7 & 1165028 & 112.7 & 1131767 \\
\hline
\end{tabular}

As can be seen the energy absorption capability of the tubes increases as the impact velocity increases. As expected the honeycomb-filled tube outperforms the empty tube in terms of specific energy absorption. Despite the extra mass due to the honeycomb filler the specific energy absorption of the filled tube is still much higher than that for an empty tube. However, the mass of the honeycomb is only $0.0006 \mathrm{~kg}$ which is negligible when comparing to the mass of a typical car which is around $1205 \mathrm{~kg}$. Thus, the honeycomb filler is a more efficient energy absorber compared to the empty tube.

Comparing the results obtained in Table 8 (maximum SEA achieved with application of NS honeycomb filler at a velocity of $48.3 \mathrm{~km} / \mathrm{h}(13.4 \mathrm{~m} / \mathrm{s})$ is $1,100,043 \mathrm{~J} / \mathrm{kg})$ with those in Table 6 (maximum SEA achieved in the Experiment with Aluminium 5052 honeycomb filler at velocity $12.5 \mathrm{~m} / \mathrm{s}$ is $71,728 \mathrm{~J} / \mathrm{kg}$ ) shows it is possible to see that the application of NS filler in circular tubes can guarantee an increase in SEA. This will increase even further with increasing velocity (up to $1,165,028 \mathrm{~J} / \mathrm{kg}$ at $112.7 \mathrm{~km} / \mathrm{h}$ ) as can be observed in Table 8. This result demonstrates a significant increase in energy absorbing ability in comparison with other typically used honeycomb based absorbers (Table 1) where a maximum SEA achieved in other research publications was not exceeding 71,728 J/kg.

\section{Conclusions}

The work presented in this paper proposes a hybrid bumper-crush can design where a recoverable tubular structure is to be integrated into the bumper beam for a mild collision situation while traditional energy absorbers are recommended for more severe collisions.

The main investigation focuses on the Negative Stiffness honeycomb (the recoverable structure), an empty tube (the traditional energy absorber), and a honeycomb- 
filled tubular element. A comprehensive study was undertaken to study numerically the behaviour of these energy-absorbing structures under crash conditions using finite element analysis.

The main results of the work presented have shown that:

1. The finite element models developed for the NSH and tubular elements (honeycomb filled and empty) have been verified with data available in the open literature;

2. It has been demonstrated in Fig. 9 that it is possible to optimise the NSH energy absorbing performance simply by choosing the most effective dimensions for the honeycomb cells. The model developed has confirmed the increase by $64 \%$ (with a value of $1.121 \mathrm{~J}$ ) as compared with the initial un-optimised element.

3. The performance of the empty and filled with NSH tubular passive safety structures was compared and, according to the results in Fig. 19, the honeycomb-filled tubes tend to display a higher peak crushing force and mean crushing force when compared with the empty tubes. This confirms that the honeycomb-filled tubes are able to absorb significantly more energy than the empty tubes.

4. It has been observed that as a rule a higher initial force is required for a start of the crumpling effect for the NSH-filled tubes.

5. It has been found that NS honeycomb structures tend to exert their strain energy in a manner that opposes the applied force, 'bouncing' the impacting object, and opposing the direction of crushing (like a spring) independently from the speed of the impact.

6. As a result it was proved that the honeycomb-filled tubes outperform the empty tubes in terms of specific energy absorption, which also increases as the impact velocity increases. Furthermore a significant increase in SEA up to 1,165,028 J/kg at $112.7 \mathrm{~km} / \mathrm{h}$ can be achieved with NS honeycomb filler, which significantly exceeds the results for some typically used Aluminium honeycombs.

7. It also has to be emphasised that the increase in efficiency can be achieved with as little mass as $0.0006 \mathrm{~kg}$ (mass of the honeycomb filler) and this is negligible when compared to the mass of the passive safety structures in a typical car.

Further validating experimental work is now planned in order to optimise the energy recovery abilities of the Negative Stiffness honeycomb and the honeycomb-filled tube for specific design applications. 


\section{References}

1. Glassbrenner D. An Analysis of Recent Improvements to Vehicle Safety. New Jersey: National Technical Information Service; 2012.

2. Frederico L. Accidentology and Development of Energy Absorbing Structures for Heavy Vehicles. [Internet]. 2005 [cited 2015 Dec 11];Available from: https://fenix.tecnico.ulisboa.pt/downloadFile/395137455460/Extended\%20abstrac t.pdf

3. Davoodi M et al.Development process of new bumper beam for passenger car: A review. Materials \& Design. 2012;40:304-313.

4. Zhang Z, Liu S, Tang Z. Design optimization of cross-sectional configuration of rib-reinforced thin-walled beam. Thin-Walled Structures. 2009;47(8-9):868-878.

5. Marzbanrad J, Alijanpour M, Kiasat M. Design and analysis of an automotive bumper beam in low-speed frontal crashes. Thin-Walled Structures. 2009;47(89):902-911.

6. Kotsikos Grasso M. Damage Tolerance of Rail Vehicle Energy Absorbers. Procedia - Social and Behavioral Sciences. 2012;48:1403-1414.

7. Keegan M. Crush Cans and the 2013 Ford Fusion. Auto Trends [Internet]. 2012 [cited 2015 Oct 19];Available from: http://www.autotrends.org/2012/05/02/crushcans-and-the-2013-ford-fusion/

8. General Electric Company. Bumper beam with crush cans. 2016;

9. Correa D et al. Negative stiffness honeycombs for recoverable shock isolation. Rapid Prototyping Journal. 2015;21(2):193-200.

10. Zarei H, Kröger M. Optimum honeycomb filled crash absorber design. Materials \& Design. 2008;29(1):193-204. 
11. Bhuyan A, Ganilova O. Crush Can Behaviour as an Energy Absorber in a Frontal Impact, Modern Practice in Stress and Vibration Analysis 2012. MPSVA 2012 IOP Publishing, Journal of Physics: Conference Series 2012;382.

doi:10.1088/1742-6596/382/1/012009

12. Deb A, Srinivas K C. Development of a new lumped-parameter model for vehicle side-impact safety simulation. Proceedings of the Institution of Mechanical Engineers, Part D: Journal of Automobile Engineering. 2008;222(10):1793-1811.

13. Patberg L, Philipps M, Dittmann R. Fibre-reinforced composites in the car side structure. Proceedings of the Institution of Mechanical Engineers, Part D: Journal of Automobile Engineering. 1999;213(5):417-423.

14. Daynes S, Weaver P M. Review of shape-morphing automobile structures: concepts and outlook. Proceedings of the Institution of Mechanical Engineers, Part D: Journal of Automobile Engineering. 2013;227(11):1603-1622.

15. Ganilova O A, Cartmell M P. An Analytical Model for the Vibration of a Composite plate containing an Embedded Periodic Shape Memory Alloy Structure. Journal of Composite Structures. 2009;92(1):39-47.

16. Cartmell M P, Ganilova O A, Gristchak V Z. Controlling Plate Vibrations by Means of Embedded Active Shape Memory Alloy Elements. Euromech 498 Colloquium. 2008;498:112-118.

17. Niknejad A, Abdolzadeh Y, Rouzegar J, Abbasi M. Experimental study on the energy absorption capability of circular corrugated tubes under lateral loading and axial loading. Proceedings of the Institution of Mechanical Engineers, Part D: Journal of Automobile Engineering. 2015;229(13):1739-1761. 
18. Olabi A, Morris E, Hashmi M. Metallic tube type energy absorbers: A synopsis. Thin-Walled Structures. 2007;45(7-8):706-726.

19. Prasad P, Belwafa J. Vehicle Crashworhtiness and Occupant Protection. Michigan: American Iron and Steel Institute; 2004.

20. Alghamdi A. Collapsible impact energy absorbers: an overview. Thin-Walled Structures. 2001;39(2):189-213.

21. All New Ford Fusion Features Unique Crush Can Safety Feature. tractionlife [Internet]. 2012 [cited 2015 Nov 17];Available from: http:/www.tractionlife.com/all-new-ford-fusion-features/

22. Petras A. Design of Sandwich Structures. 1998;

23. HexWeb Honeycomb Attributes and Properties [Internet]. 1st ed. Hexcel Composites; 1999 [cited 2015 Nov 12]. Available from: http://www.hexcel.com/Resources/DataSheets/Brochure-Datasheets/Honeycomb_Attributes_and_Properties.pdf

24. Yin $\mathrm{H}$, Wen $\mathrm{G}$, Hou $\mathrm{S}$ et al. Crushing analysis and multiobjective crashworthiness optimization of honeycomb-filled single and bitubular polygonal tubes. Materials \& Design. 2011;32(8-9):4449-4460.

25. Guden M. Quasi-Static Axial Crushing Behavior of Honeycomb-Filled ThinWalled Aluminum Tubes. The Open Materials Science Journal. 2011;5(1):184193.

26. Said M, Tan C. Aluminium honeycomb under quasi-static compressive loading: an experimental investigation. Suranaree Journal of Science and Technology. $2009 ; 16(1): 1-8$. 
27. Marzbanrad J, Mehdikhanlo M, Pour A. An energy absorption comparison of square, circular and elliptic steel and aluminium tubes under impact loading. Turkish Journal of Engineering and Environmental Sciences. 2009;33(3):159166.

28. Thornton P. Energy Absorption in Composite Structures. Journal of Composite Materials. 1979;13(3):247-262.

29. Yan W, Durif E, Yamada Y et al. Crushing Simulation of Foam-Filled Aluminium Tubes. MATERIALS TRANSACTIONS. 2007;48(7):1901-1906.

30. Kumar PR, Vitala HS. Evaluation for Energy Absorbing Capacity of Concentric Aluminium Tubes Filled With Foam of Different Density. International Journal of Mechanical and Industrial Technology. 2014;2(1):113-124.

31. Duerig T. Engineering aspects of shape memory alloys. London: ButterworthHeinemann; 1990.

32. Bayraktar E, Khalid F, Levaillant C. Deformation and fracture behaviour of high manganese austenitic steel. Journal of Materials Processing Technology. 2004;147(2):145-154.

33. Restrepo D, Mankame N, Zavattieri P. Phase transforming cellular materials. Extreme Mechanics Letters. 2015;4:52-60.

34. Small Overlap Frontal Crashworthiness Evaluation [Internet]. 1st ed. Ruckersville: Insurance Institute for Highway Safety; 2014 [cited 2016 Jun 23]. Available from: http://www.iihs.org/media/ec54a7ea-1a1d-4fb2-8fc3b2e018db2082/691118402/Ratings/Protocols/current/small_overlap_test_protocol .pdf

35. Wierzbicki T. Crushing analysis of metal honeycombs. International Journal of Impact Engineering. 1983;1(2):157-174. 
36. Small Cars Still Need to Improve in Overlap Front Crash Test: IIHS [Internet]. Claims Journal. 2014 [cited 2015 Oct 16];Available from: http://www.claimsjournal.com/news/national/2014/07/30/252580.htm

37. golf-vii pricing \& specifications : Volkswagen UK [Internet]. Volkswagen.co.uk. 2016 [cited 2015 Nov 19];Available from: http://www.volkswagen.co.uk/new/golf-vii/which-modelcompare/details/1354\#!\#tech-spec

38. General rules, techniques and advice for all drivers and riders (103 to 158) - The Highway Code - Guidance - GOV.UK [Internet]. Gov.uk. 2016 [cited 2016 Jun 23];Available from: https://www.gov.uk/guidance/the-highway-code/general$\underline{\text { rules-techniques-and-advice-for-all-drivers-and-riders-103-to-158 }}$

39. The Aluminium Automotive Manual [Internet]. 1st ed. European Aluminium Association; 2011 [cited 2016 Mar 6]. Available from: http://europeanaluminium.eu/media/1511/aam-design-5-case-study-cms.pdf

40. Standard for verification and validation in computational fluid dynamics and heat transfer. New York, NY: American Society of Mechanical Engineers; 2009.

41. Klat T, Haberman M, Seepersad C. Selective laser sintering of negative stiffness mesostructures for recoverable, nearly-ideal shock isolation. 24th International SFF Symposium - An Additive Manufacturing Conference, SFF 2013. $2013 ;: 1010-1022$.

42. CES EduPack 2014. Cambridge: Granta Material Intelligence; 2014.

43. Ellobody E, Feng R, Young B. Finite element analysis and design of metal structures.

44. Using Shell Elements for Your FEA Simulation | HiTechFEA.com [Internet]. Hitechfea.com. 2015 [cited 2016 Feb 7];Available from: 
http://www.hitechfea.com/fea-knowledgebase/using-shell-elements-for-your-feasimulation/

45. Zarei HKröger M. Multiobjective crashworthiness optimization of circular aluminum tubes. Thin-Walled Structures. 2006;44(3):301-308.

46. Yamazaki KHan J. Maximization of the crushing energy absorption of tubes. Structural Optimization. 1998;16(1):37-46. 


\section{List of figure captions}

Figure 1. Negative stiffness honeycomb [9]

Figure 2. Optimisation process of the tubular structure applying NSH

Figure 3. (a) 25\% offset condition [7], (b) Impact barrier dimension [7]

Figure 4. Location of the energy absorbers and impact barrier [7]

Figure 5(a). NS honeycomb dimensions [9], (b) NS honeycomb model

Figure 6. Loading and boundary conditions for the numerical analysis

Figure 7. Force displacement graph of (a) the numerical simulation and (b) the model developed in [9]

Figure 8. Symbolic representation of the optimisation performed for the NS honeycomb [41]

Figure 9. Force displacement behaviour of the initial (based on results in [41]) and optimised NS honeycomb

Figure 10. Deformation results for (a) initial model and (b) optimised model

Figure 11. Finite element model adopted for the bumper beam impact test

Figure 12. Characteristic parameters of the honeycomb filler

Figure 13. (a) - Experimental [10] and (b) - finite element deformation for the Aluminium 6060 tube [10] filled with Aluminium 5052 honeycomb [23]

Figure 14. Results of (a) the finite element model of the honeycomb filled tube results and (b) experimental tests of both the honeycomb-filled and empty tubes [10]

Figure 15. Physical arrangement of the impact ball and the honeycomb-filled tube

Figure 16. Specific energy absorption versus impact velocity for the NS honeycomb

Figure 17. Force-displacement graph for (a) $14.8 \mathrm{~km} / \mathrm{h}$ and (b) $48.3 \mathrm{~km} / \mathrm{h}$ impact loading

Figure 18. Force-displacement under impact at the speed of (a) $96.6 \mathrm{~km} / \mathrm{h}$ and (b) 112.7 $\mathrm{km} / \mathrm{h}$

Figure 19. Comparison of NS honeycomb-filled and empty tubes at different speeds 